\title{
POSITIVISMO, DERECHO Y JUSTICIA EN LA CONSTITUCIÓN COLOMBIANA DE 1991 *
}

\author{
Positivism, law and justice in the Colombian \\ Constitution 1991
}

Eduardo Matyas Camargo**

Corporación Universitaria Republicana. Bogotá, D.C.

Recepción: 2 de julio de 2016. Aceptación: 28 de octubre de 2016.

DOI: http://dx.doi.org/10.21017/Rev.Repub.2016.v21.a15

"Negando el instinto de libertad, demostraremos que los humanos son una mutación letal, un punto muerto evolutivo. Alimentándolo, si es real, podemos hablar maneras de abordar tragedias y problemas humanos de enorme magnitud» 1 .

\section{RESUMEN}

El ordenamiento jurídico colombiano se halla erigido sobre la primacía de la Constitución política, de conformidad con los planteamientos del llamado positivismo jurídico, cuyo máximo exponente fue Hans Kelsen, en donde las demás normas (Leyes, Decretos, ordenanzas, etc.), se hallan en un ordenamiento piramidal que le da su validez formal.

Sin embargo, a partir de nuevos desarrollos teóricos y jurídicos en el orden internacional, la Corte Constitucional y el operador jurídico realizan un control abstracto y material sobre la subordinación formal y sobre los contenidos sustantivos de las normas, excluyéndolas del orden legal o inaplicándolas cuando presuponen que desconocen la norma fundante o van contra el deber ser -formal y material- del orden constitucional o supraconstitucional. Es decir, las normas internas

* Este artículo es producto del proyecto de investigación: Proceso de paz y justicia transicional, desarrollado dentro de la línea de investigación Derecho Penal y Política Criminal del Grupo Derecho Público, perteneciente al Centro de Investigaciones de la Corporación Universitaria Republicana, reconocido por Colciencias.

** Abogado de la Universidad Autónoma de Bucaramanga, con Especialización en Derecho Constitucional en la Universidad Nacional de Colombia. Estudios de Maestría en filosofía del derecho interpretación jurídica en la Universidad Libre. Investigador de la Corporación Universitaria Republicana, profesor de DIH y DD.HH. en la Maestría de la Universidad Pedagógica y Tecnológica de Colombia. Correo electrónico: ematyasdih@ hotmail.com

1 CHOMSKY, Noam, El miedo a la Democracia. Editorial Crítica, Barcelona 1992, pág. 401. 
del Estado colombiano no pueden desconocer el ordenamiento constitucional y convencional como norma internacional vinculante so pena de ser excluidos del orden legal. Lo anterior no resulta suficiente para que el ordenamiento jurídico y su aplicación por los operadores judiciales y administrativos transforme la realidad social objeto material del paradigma constitucional.

De conformidad con lo anterior, se aborda el estudio de la normatividad colombiana confrontándola con el ordenamiento jurídico internacional, la validez de la norma positiva y alcance que los operadores judiciales le dan a través de la hermenéutica y aplicación efectiva en la solución de los problemas sociales, resaltando las limitaciones que el orden jurídico en sí contiene para transformar la realidad social.

Palabras clave: Derecho, constitución, positivismo, derecho internacional, justicia, equidad, Estado, control constitucional, democracia.

\section{ABSTRACT}

The Colombian legal system is based on the primacy of the political Constitution, in accordance with the approaches of the so-called juridical positivism, whose maximum exponent was Hans Kelsen, where the other norms (Laws, decrees, ordinances, etc.) are found In a pyramidal order that gives it its formal validity.

However, from new theoretical and juridical developments in the international order, the Constitutional Court and the legal operator perform an abstract and material control on the formal subordination and on the substantive contents of the norms, excluding them from the legal order or ignoring them when they presuppose that do not know the founding norm or go against the duty to be - formal and material - of the constitutional or supraconstitutional order. That is to say, the internal norms of the Colombian State cannot ignore the constitutional and conventional order as a binding international norm under penalty of being excluded from the legal order. This is not enough for the legal order and its application by judicial and administrative operators to transform the material social reality of the constitutional paradigm.

In accordance with the above, the study of Colombian law is dealt with by comparing it with the international legal system, the validity of the positive norm and the scope that judicial operators give through hermeneutics and effective application in solving social problems, highlighting the limitations that the legal order itself contains to transform social reality.

Key words: Law, constitution, positivism, international law, justice, equity, state, constitutional control, democracy. 


\section{PROBLEMA JURIDICO DE INVESTIGACIÓN}

El orden jurídico-constitucional de 1991 construido sobre el paradigma del Estado social de derecho presupone las nuevas instituciones resolverán los problemas sociales a través de la norma jurídica, dentro de los cauces legales. Se pretendió que el derecho podía solucionar el orden social injusto, ya que las normas expedidas por un órgano legítimo de elección democrático-popular deberían responder a los problemas de las mayorías, como máxima expresión de la democracia representativa.

Sin embargo, pese a la erección de la norma superior programática de un Estado social de derecho, el desarrollo legislativo y el esfuerzo de la interpretación y aplicación por el órgano de tutela constitucional que buscaría garantizar los principios políticos, sus valores y contenidos de la norma superior, no se logra resolver a través de la acción política democrática y jurídica (el activismo judicial), los postulados del Estado Social de Derecho, revirtiendo la profunda desigualdad económica y social, y la amplísima disgregación política de la mayoría que desdibuja la pretensión constitucional.

De allí surge la necesidad de establecer el alcance y limitaciones del orden jurídico-constitucional en la solución de los problemas reales que el paradigma constitucional establece, de comprender las razones jurídico-institucionales de porque la normatividad no resulta en sí misma suficiente y adecuada para transformar la realidad social destinataria de las normas superiores, a través del análisis dialéctico de confrontación entre las normas jurídicas positivas con la realidad social, el anclaje en el pasado de las instituciones que no logra evolucionar a través de la nueva formulación jurídica atravesada por los intereses sociales en pugna y la hermenéutica que determinan el alcance de las normas.

\section{METODOLOGÍA}

En el estudio de la preponderancia del ordenamiento jurídico colombiano se interrelacionan diferentes formas de abordar el objeto de la investigación, como es la existencia normativa positiva que conlleva al abordaje a través del método deductivo, que facilita la comparación del ordenamiento jurídico internacional con el ordenamiento interno, dando lugar a la confrontación con las realidades sociales que involucran en análisis deductivo a los resultados de la aplicación del ordenamiento jurídico a la realidad ontológica y las soluciones analógicas de los operadores judiciales, para llegar a conclusiones dialécticas de la superación del problema objeto de la investigaciones a través de método analítico que considera los diferentes componentes involucrados en el proble- 
ma como la política, el derecho, la acción de masas, los operadores judiciales, y el ordenamiento jurídico internacional, entre otros.

\section{RESULTADOS INVESTIGATIVOS}

Las nuevas constituciones de finales del siglo XX, como las de Alemania, España (1978), Brasil (1988) y Colombia (1991), no se limitan a establecer las competencia de los órganos o a establecer la estructura funcional del Estado, sino son prolijas en consagrar derechos fundamentales o sustantivos, que condicionan las actuaciones del Estado (de sus órganos y funcionarios), y determinan los fines del mismo. Este desarrollo constitucional ha sido denominado por algunos teóricos como neoconstitucionalismo, diferenciándolo del viejo constitucionalismo liberal decimonónico. ${ }^{2}$

Una de las características de nuevo constitucionalismo es la supremacía de la norma constitucional sobre las demás normas legales y supralegales, su subordinación a principios, en el decir de Dworkin, no todos constitucionalizados o positivados ${ }^{3}$. Esa supremacía de la norma constitucional tuvo un fuerte y definitivo impulso en los trabajos de Kelsen, especialmente en la «Teoría pura del derecho» ${ }^{4}$.

Desarrollos posteriores del derecho constitucional, partiendo de la aceptación de la supremacía de la norma constitucional, le dan nuevos desarrollos no solo en cuanto a la legitimidad de la norma por su dependencia de la norma fundante, sino en cuanto a su contenido material, partiendo de los valores sustantivos introducidos en las nuevas constituciones, como derechos fundamentales, que son la base de derechos subjetivos.

Esos nuevos derechos sustantivos incorporados a las constituciones tienen igualmente una presuposición hipotética en el derecho internacional, acogiendo los apotegmas de Kelsen, específicamente en las convenciones y tratados internacionales de derechos humanos, que en la medida en que estén conforme a estos ordenamientos reciben validez, apartándose en este aspecto del postulado kelseniano. Podríamos pensar con Hart, que entonces...»se utiliza una regla secundaria de reconocimiento para la identificación de reglas primarias de obligación». ${ }^{5}$

2 CARBONEL, Miguel. Neoconstitucionalismo, Trotta, Madrid, 2006, pp. 77 y ss.

3 DWORKIN, Ronald. Los derechos en serio. Traducción de Marta Guastavino, Editorial A, Barcelona, 3ra reimpresión, 1997, pág. 99.

4 KELSEN, HANS. Teoría Pura del Derecho, Edit. Porrúa. S.A., Séptima Edición, México, 1993, pág. 202

5 HART, H.L.A. El concepto de Derecho, Abeledo Perrot, Buenos Aires, Pág. 125. 


\subsection{El positivismo}

Con la expresión positivismo se designa un conjunto de corrientes filosóficas y científicas, sobre las cuales no hay una unidad de criterio, dado el cumulo de autores, con acepciones diferentes y aun contradictorias, que han disertado sobre el tema. El término «positivismo» tuvo su origen en Augusto Comte, autor que desarrolló no solo una «filosofía positivista», que comprendía una doctrina acerca de la ciencia, sino también una doctrina sobre la sociedad y sobre las normas necesarias para reformas la sociedad conduciéndola a una «etapa positiva».

Siguiendo los planteamientos de Ulises Schmill, «El positivismo no es un paradigma determinado, concluido, definitivo, como un código de leyes caído del cielo, sino una posición filosófica ante los problemas más acuciantes del conocimiento y la moralidad. El postulado fundamental es que la ciencia es el único criterio de verdad, la ciencia es la «medida» de lo que es y de lo que no es, de lo que existe y de lo que no existe, así como de aquello sobre lo que tiene sentido la formulación de preguntas y la obtención de las respuestas correctas. Si la Edad Media fue una época en la que la totalidad de la vida estaba permeada por la religión, al grado que no existía una sola actividad que no tuviera una coloración ultramundana, el positivismo creó un ambiente radicalmente antimedieval, en donde ninguna cuestión religiosa tenía cabida o podía legitimarse. Si la ciencia es el único conocimiento válido, sólo los hechos empíricos son objeto de conocimiento posible. El positivismo niega la posibilidad de cualquier otro conocimiento que no sea el conocimiento de hechos empíricos observables y, por tanto, niega la existencia de fuerzas o acontecimientos de carácter trascendente, ultramundano o metafísico ${ }^{6}$.

\subsection{El positivismo científico}

Esta corriente de pensamiento tiene como característica la defensa de un monismo metodológico (teoría que afirma que hay un solo método aplicable en todas las ciencias). La explicación científica ha de tener la misma forma en cualquier ciencia si se aspira a ser ciencia, específicamente el método de estudio de las ciencias físico-naturales. Los elementos que se encuentran relacionados por las leyes científicas son experiencias puras que no son ni mentales ni físicas, sino datos neutrales susceptibles de ser verificados por todas las ciencias, las que se diferencian entre si por la particular manera d relacionar estos elementos.

6 SCHMILL O., Ulises. El Positivismo Jurídico. En El Derecho y la Justicia. Enciclopedia Iberoamericana de Filosofía. Editorial Trotta, Madrid, 1996 pp. 67 
Para el positivismo el objetivo del conocimiento es explicar causalmente los fenómenos por medio de leyes generales y universales, lo que le lleva a considerar a la razón como medio para otros fines (razón instrumental). La forma que tiene de conocer es inductiva, despreciando la creación de teorías a partir de principios que no han sido percibidos objetivamente. La ciencia no puede dar explicación de por que acontecen los fenómenos, sino de cómo acontecen dichos fenómenos.

\subsection{El positivismo jurídico}

El positivismo jurídico es la teoría del derecho que solo acepta como objeto de estudio el derecho positivo. El positivismo jurídico se desarrolla sobre la base de los principios del positivismo científico. Siendo diversos los tratadistas ${ }^{7}$ que han desarrollado y hecho aportes importantes al positivismo jurídico, nos basaremos fundamentalmente en Kelsen por ser tal vez el más representativo, y porque de él se tomaran otras aportaciones como la jerarquización escalonada de las normas, base de la supremacía constitucional.

Según Carl Schmitt, para la ciencia jurídica del siglo XIX «... positivismo significaba ante todo algo polémico: la negación de todo lo «extralegal», de todo lo que sea derecho creado por la legislación humana, sea derecho divino, natural, o racional. El pensamiento jurídico queda así convertido en pensamiento legal». ${ }^{8}$

Para Kelsen el positivismo jurídico presupone como derecho el orden coactivo de normas que regulan su propia creación, llamado concepto dinámico del derecho positivo, según el cual, las normas de la moral, el derecho natural, y las normas convencionales no pueden formar parte integrante del derecho positivo, porque ni su creación ni sus contenidos no dependen de otras normas jurídicas. Al respecto puede aplicársele el aforismo de Kelsen: «El fundamento de validez de una norma solo puede encontrarse en la validez de otra norma» 9 .

El profesor Germán Cisneros Farías sintetiza el positivismo jurídico como «un conjunto de normas puesta por los seres humanos, a través del Estado, mediante un procedimiento formalmente valido, con la intención o voluntad de someter la conducta humana al orden disciplinario por el acatamiento de esas normas». ${ }^{10}$

7 Entre los más destacados J. Benthan (1748-1832); Austin (1790-1859), H. L. A. Hart (19071992).

8 SCHMITT, Carl. Sobre los tres modos de pensar la ciencia jurídica. Trad. Monserrat Herrera, Técnos, Madrid, 1996, pág. 34.

9 Ibid., 201.

10 CISNEROS FARÍAS, Germán. Teoría del Derecho, Editorial Trillas, 2da edición, México 2000, pág. 29. 
Al resumir Kelsen su obra principal, precisa que «la teoría pura del derecho es positivismo jurídico», y que en tanto ciencia del derecho positivo, se opone a la teoría del derecho natural, que busca la esencia del derecho en una justicia transcendente.

Otro de los problemas planteados allí por Kelsen, es la cuestión de saber que es lo que constituye la unidad en una pluralidad de normas jurídicas, es decir esa unidad que se designa como sistema jurídico u orden jurídico, de donde se deriva sus acotaciones sobre la estructuración escalonada de las normas, donde deriva su valides ${ }^{11}$.

\section{ESTRUCTURA ESCALONADA DEL ORDEN JURÍDICO}

HANS KELSEN en su obra ya citada «Teoría Pura del Derecho», expone brillantemente las tesis sobre de la jerarquización escalonada de las normas jurídicas en la estructura jurídico de un Estado, a manera de una pirámide sobre la cual se escalona dicha jerarquía normativa, que comúnmente recibe el nombre de supremacía constitucional, considerada en los inicios del siglo XX como un principio constitucional, y en las modernas Constituciones como una preceptiva normativa.

Esta teoría utiliza la idea de norma fundamental como presuposición hipotética de todo conocimiento jurídico. Dicha norma fundamental representa la razón de validez de todas las normas que pertenecen a un mismo orden jurídico.

«Como se indicó, -escribe Kelsen- la norma que representa el fundamento de validez de otra norma es, en su respecto, una norma superior; pero la búsqueda del fundamento de validez de una norma no puede proseguir hasta el infinito, como la búsqueda por la causa de un efecto. Tiene que concluir en una norma que supondremos la última, la suprema. Como norma suprema tiene que ser presupuesta, dado que no puede ser impuesta por una autoridad cuya competencia tendría que basarse en una norma aún superior. Su validez no puede derivarse ya de una norma superior, ni puede volver a cuestionarse el fundamento de su validez. Una norma semejante, presupuesta como norma suprema, será designada aquí como norma fundante básica (Grundnorm). Todas las normas cuya validez pueda remitirse a una y misma norma fundante básica, constituyen un sistema de normas, un orden normativo. La norma fundante

11 KELSEN, Hans. ¿Qué es la Teoría pura del derecho? Distribuciones Fontamasra S.A., Doceava reimpresión, México, 2007, pág. 19. 
básica es la fuente común de la validez de todas las normas pertenecientes a uno y el mismo orden ${ }^{12}$.

Con posterioridad a la primera edición de la Teoría Pura, Kelsen complementa su planteamiento haciendo depender la validez del ordenamiento jurídico del derecho internacional, como norma fundante, cuyo desarrollo normativo tuvo primer desarrollo en el derecho de gentes, y la efímera Sociedad de las Naciones, adquiriendo una gran dinámica con posterioridad a la Segunda Guerra Mundial y el desarrollo de sistemas jurídicos internacional -ONU- y regionales, hoy vigentes y en pleno desarrollo.

\section{EL ORDEN JERÁRQUICO NORMATIVO COLOMBIANO}

El 4 de julio de 1991 fue promulgada la nueva constitución política, definiendo que Colombia es un Estado social y democrático de derecho, organizado en forma de república unitaria, fundada en el respeto a la dignidad humana, el trabajo y la solidaridad, en la prevalencia del interés general, entre otros principios.

En su artículo 4 establece la supremacía de la Constitución: la constitución es norma de normas. Seguidamente consagra que «en todo caso de incompatibilidad entre la constitución y la ley u otra norma jurídica, se aplicaran las disposiciones constitucionales».

A su vez, el artículo 93 instituye el bloque de constitucionalidad, a través del cual los tratados internacionales ratificados por el Congreso, que reconocen los derechos humanos y que prohíben su limitación en los estados de excepción, prevalecen en el orden interno. Se establece igualmente que los derechos y deberes consagrados en la Carta, se interpretaran de conformidad con los tratados internacionales sobre derechos humanos ratificaos por Colombia.

En estas normas constitucionales se ve que los aportes de Kelsen sobre este punto tienen una aplicación directa y son fundamento de la validez o no de las normas subordinadas de orden interno, regla en que se ha fundamentado en numerosas sentencias la Corte Constitucional y otros operadores jurídicos.

Por otra parte, el artículo 241 de la Carta consagra que la Corte Constitucional le corresponde la guarda de la Constitución, a través de control de

12 KELSEN, Hans. Teoría Pura del Derecho, Edit. Porrúa. S.A., Séptima Edición, México, 1993, pág. 202 
constitucionalidad sobre los actos reformatorios de la misma, sobre la constitucionalidad de la convocatoria a referendo o a una asamblea constituyente, consultas populares y plebiscitos, sobre vicios de procedimiento, y sobre leyes y decretos con fuerza de ley, y la exequibilidad de los tratados internacionales.

\subsection{Control constitucional formal}

En concordancia con lo anterior, la Constitución consagra en forma expresa el derecho que tiene todo ciudadano a interponer acciones públicas en defensa de la constitución y la ley (40.6), como una derivación del derecho de participación en la conformación, ejercicio y control del poder político.

En Colombia el control constitucional es difuso,, ya que no es ejercido por un solo órgano, sino por varios: por la Corte Constitucional como función esencial y permanente, por su condición de órgano supremo de jurisdicción constitucional; por el Consejo de Estado como órgano complementario respecto a determinadas normas jurídicas (decretos reglamentarios), por los Tribunales Administrativos (ordenanzas, acuerdos, etc.), e incluso por las autoridades administrativas y operadores judiciales, a través de la excepción de inconstitucionalidad, en casos concretos y con efecto interpartes.

«Cuando el juez o funcionario administrativo vislumbre la transgresión normativa, en cualquier caso, - sostiene el Consejo de Estado aplicando la excepción de constitucionalidad y la primacía normativa de la Constitución- es su deber hacer prevalecer el ordenamiento fundamental sobre la normatividad inferior, con el objeto de mantener incólume el orden jurídico, en su escala jeraquizante y, además, propendiendo por el equilibrio de la distribución de competencias y garantizando la protección de los derechos de las personas, sean o no fundamentales; pilares jurídico-políticos del Estado Social de Derecho». (Providencia de octubre 2 de 1996, Recurso de Insistencia, Magistrado Ponente, Dr. ERNESTO REY CANTOR, actor Gilberto y Miguel Rodríguez Orejuela, Exp. 7864)-

\subsection{Control constitucional material o sustantivo}

La Carta de 1991 prevé no solo el control formal de la norma jurídica sino también el control material o sustantivo, cuando estas normas contravienen los principios constitucionales, o los tratados de derechos humanos ratificados por Colombia. En el artículo 241.4, 241,5 y 241.8 se establece que la Corte Constitucional ejerce el control formal y material sobre las leyes demandadas o sujetas a contra automático, contra los decretos legislativos con fuerza de ley, y proyectos de ley objetados por el ejecutivo. El 241.10 establece además 
que sí alguna norma de un tratado «multilateral» es declarada inexequible, se deberá hacer reserva respecto a esta norma al firmar el tratado.

Este control sustantivo sobre principios y valores constitucionales y derecho internacional opera conforme a otras normas de reconocimiento, para que las normas legales subordinadas tengan validez.

A partir de la iniciación de labores, La Corte Constitucional ha elaborado una consistente jurisprudencia, que busca, en su decir, hacer realidad los fines esenciales del Estado social de Derecho en su conjunto, entre los cuales ocupa un lugar preeminente la efectividad de los principios, derechos y deberes consagrados en la Constitución, al punto, que a través de las llamadas sentencias integradoras en juez constitucional proyecta los mandatos constitucionales en la legislación ordinaria. Al respecto de lo anterior la Corte Constitucional expresó:

«La sentencia integradora es una modalidad de decisión por medio de la cual, e juez constitucional, en virtud del valor normativo de la Carta (C.P. art. 4), proyecta los mandatos constitucionales en la legislación ordinaria, para de esa manera integrar aparentes vacíos normativos o hacer frente a inevitables indeterminaciones del orden legal. En ello reside la función integradora de la doctrina constitucional, cuya obligatoriedad como fuente de derecho, ya ha sido reconocida por esta Corporación. Y no podía ser de otra forma, porque la constitución no es un simple sistema de fuentes, sino que es en si misma una norma jurídica, y no cualquier norma, sino la norma suprema (C.P. art. 4), por lo cual sus mandatos irradian y condicionan la validez de todo ordenamiento jurídico ${ }^{13}{ }^{\text {». }}$

Esa modalidad integradora de algunas sentencias de la Corte Constitucional se hace imprescindible a partir de la «textura abierta» de la Constitución que posibilita la dificultad de acordar criterios unívocos, como es mencionado por Cristina Motta en «Ética y conflicto» ${ }^{14}$.

\subsection{Subordinación de las normas legales al derecho internacional}

El control constitucional que realiza la Corte Constitucional en Colombia, no se limita a la validación o exclusión de las normas jurídicas, previa constatación de que los trámites legislativos y formales se cumplan estrictamente, ni a verificación

13 http://www.corteconstitucional.gov.co/RELATORIA/Autos/2009/A256-09.htm

14 MOTTA, Cristina. Ética y Conflicto, Uniandes y Tercer Mundo Editores, primer edición, 1995, pág. 232. 
de que las leyes y decretos legislativos en su contenido material o sustantivo estén conforme a los valores o principios constitucionales.

También este control constitucional sustantivo se hace extensivo al control constitucional respecto a las leyes que incorporan tratados internacionales. Respecto a esta tipo de normatividad, además del control respecto a la convergencia con la normatividad constitucional, el control conlleva la constatación de que esta normatividad internacional que se va a incorporar a la legislación nacional, a través de la cual el Estado adquiere además obligaciones internacionales, conlleva el respeto a los valores y principios integradores de la Carta constitucional, ya que en caso contrario no puede ser ratificado, o en caso de no serlo totalmente contrario a la Carta, hacer las reservas respecto a las normas contrarias.

Una vez ratificado y vigente la ley que incorpora el tratado internacional, cuyo control constitucional garantiza la concordancia e integralidad con la Carta, su normatividad tiene prevalencia sobre las demás normas internas. Al respecto, sobre el respeto a los principios y valores supremos, y la subordinación de las normas internas al derecho internacional de los derechos humanos, la Corte Constitucional ha acotado al respecto:

"Previene el artículo 1o. que Colombia es un Estado Social de Derecho, con lo cual se quiere significar que el objeto de la atención del Estado es la persona humana, por su característica trascendental de poseer una dignidad que habrá de reconocerse y respetarse. Es entonces con esta nueva óptica que el Estado debe ponerse al servicio del ser humano y no estar éste al servicio y disposición de aquél. Se coloca así en pedestal especial a la persona y a partir de ello se instituyen expresamente a su favor derecho fundamentales que han de ser observados. El artículo 2o. ibídem reafirma que los fines del Estado son: servir a la comunidad, promover la prosperidad general y garantizar la efectividad de los principios, derechos y deberes consagrados en la Constitución. A las autoridades se les encomienda la tarea de velar por la protección de todas las personas residentes en Colombia en su vida, honra, bienes, creencias y demás derechos y libertades y para asegurar el cumplimiento de los deberes sociales del Estado y de los particulares.

«En múltiples oportunidades este cuerpo judicial ha puesto de resalto que el respeto y efectividad de los derechos fundamentales, es eje principalísimo en la axiología que inspira la Carta de 1991.

De ahí que el control jurídico de constitucionalidad que esta adscribe a la Corte Constitucional, se instituya junto con otros mecanismos -como la tutela- fundamentalmente para la defensa de los derechos fundamentales. 
Ese mismo telos explica en la Carta de 1991 una serie de dispositivos amplificadores del contenido tutelar en esta materia, en la cual el Constituyente plasmó la idea de prevalencia de los valores y principios por sobre su consagración positiva al contemplar los mecanismos de protección que a manera puramente ejemplificativa se citan a continuación:

1. En el artículo 93, al consagrar la primacía en el orden interno de los tratados y convenios internacionales ratificados por el Congreso, que reconocen los derechos humanos y que prohíben su limitación en los estados de excepción;

2. Al preceptuar en esa misma disposición que el ius cogens o derecho imperativo sobre derechos humanos es criterio interpretativo esencial de la Carta de Derechos;

3. Al indicar de manera categórica en su artículo 94 que la enunciación de los derechos y garantías contenidos en la parte dogmática es puramente indicativa, al señalar que tal enunciación y la contenida en los convenios internacionales vigentes,

«...no debe entenderse como negación de otros que, siendo inherentes a la persona humana, no figuren expresamente en ellos.»

4. Al incorporar al derecho interno sin necesidad de ratificación el ius cogens en materia de derecho internacional humanitario, y demandar su observancia universal e imperativa, al disponer en su artículo 215-2 que durante los estados de excepción «no podrán suspenderse los derechos fundamentales» que »en todo caso se respetarán las reglas del derecho internacional humanitario.»

En relación con la fuerza vinculante y obligatoria del ius cogens, esta Corte ha tenido oportunidad de sostener lo siguiente en la sentencia C-574, del 28 de octubre de 1992:

"Los tratados en los que se plasma el derecho internacional humanitario son, por el contrario, una buena muestra de que en ellos los Estados contratantes no aparecen en condición de reales o potenciales beneficiarios sino únicamente como obligados. Además, la fuerza vinculante de ellos no depende ya de la de la voluntad de un Estado en particular, sino, primordialmente, del hecho de que la costumbre entre a formar parte del corpus del derecho internacional. Por lo demás, en estos tratados no opera el tradicional principio de la reciprocidad ni tampoco, - como lo pone de presente la Corte Internacional de Justicia en el caso del conflicto entre Estados Unidos y Nicaragua -, son susceptibles de reserva.....»

«...Luego de la entrada en vigencia de la Carta de Naciones Unidas, son obligatorias todas las normas relativas a la protección de los derechos humanos fundamentales y a la prohibición del uso de la fuerza (art. 2-4). 
Esta idea ha sido recogida por el artículo 23 de la Convención de Viena sobre el derecho de los tratados del 23 de mayo de 1969, según el cual es nulo todo tratado que esté en oposición con una norma imperativa del derecho internacional general, entendiendo por ello, «una norma aceptada y reconocida por la comunidad internacional de Estados en su conjunto como norma que no admite acuerdo en contrario»

$\ldots$

«... En sintesis, los principios del derecho internacional humanitario plasmados en los Convenios de Ginebra y en sus dos Protocolos, por el hecho de constituir un catálogo ético mínimo aplicable a situaciones de conflicto nacional o internacional, ampliamente aceptado por la comunidad internacional, hacen parte del ius cogens o derecho consuetudinario de los pueblos. En consecuencia, su fuerza vinculante proviene de la universal aceptación y reconocimiento que la comunidad internacional de Estados en su conjunto le ha dado al adherir a esa axiología y al considerar que no admite norma o práctica en contrario. No de su eventual codificación como normas de derecho internacional... De ahí que su respeto sea independiente de la ratificación o adhesión que hayan prestado o dejado de prestar los Estados a los instrumentos internacionales que recogen dichos principios»

El derecho internacional humanitario es, ante todo, un catálogo axiológico cuya validez absoluta y universal no depende de su consagración en el ordenamiento positivo» ${ }^{15}$.

Debe resaltarse que esta posición de la Corte Constitucional no alcanza a analizar todo el desarrollo del derecho internacional económico que ha tenido el mundo en los dos últimos decenios a partir de la profundización del neoliberalismo en el mundo y en Colombia a partir de la administración Gaviria, tal como lo advierte YVETS DEZALAY y DAVID M. TRUBEK, en el artículo «LA REESTRUCTURACION GLOBAL Y EL DERECHO»: «El campo jurídico, como entendemos este términos, tiene su campo o 'eje' en el Estado nación y en el orden normativo que origina del derecho estatal. Pero los campos jurídicos son más complejos y multidimensionales y lo serán mucho más con el tiempo si continúan los procesos de «globalización». ${ }^{16}$

15 CORTE CONSTITUCIONAL, C 276 de 1993. 22 de julio de 1993. M.P. VLADIMIRO MESA.

16 DEZALAY, Yvets y TRUBEK, David M., en el artículo «LA REESTRUCTURACION GLOBAL Y EL DERECHO. En «PENSAMIENTO JURIDICO, Universidad Nacional de Colombia, No. 1, 1994. pág. 11. 


\section{VALORES SUPERIORES CONSTITUCIONALES}

Si con Kelsen las normas de reconocimiento se hallan atadas a la norma fundamental y la imputación ${ }^{17}$, a partir de las críticas que Dworkin le formula a Hart, y a las limitaciones del positivismo, pese a que éste aceptaría que «hay por lo menos algunas reglas de derecho que no son obligatorias porque sean válidas bajo normas establecidas por una regla maestra, sino que lo son como la regla maestra, porque la comunidad lo acepta como válidas». ${ }^{18}$, Dworkin ahonda las críticas al positivismo e los términos en que ha ese momento se había planteado, y sugiere nuevos elementos que lo llevan a la valoración de la moral y el derecho por su contenido.

Esa regla maestra está conformada, en el Estado Social de Derecho, por los principios y valores constitucionales, entre ellos a justicia como equidad, en el entendido de «una concepción política de la justicia para el caso especial de la estructura básica de una sociedad moderna», en el entendido de RAWLS. ${ }^{19}$

Pero puede haber una situación antitética en «en el caso en que las estructuras políticas no coincidan con los modelos normativos de una sociedad, se las considerará como disfuncionalidad de un conjunto mal integrado, lo que especificaría su ilegitimidad ${ }^{20}$, como anota Poulantzas, situación hoy normal, por la influencia de los actores económicos en el derecho, en donde prima el afán de ganancia por encima de los valores del Estado social de derecho, reivindicando las viejas apotegmas marxistas sobre el Estado y el derecho.

De conformidad con lo anterior, el «modelo social e derecho» no tiene realización real, pese a las formulaciones en el «sistema jurídico», en donde teóricamente se consagran los derechos fundamentales propios de un Estado social, pero que como no tiene su realización real cuando más se acerca a los derechos y libertades planteadas por el derecho burgués, sin perder de vista que «los órdenes jurídicos concretan no solo distintas variantes de la realización de los mismos derechos y principios; en ellos se reflejan también paradigmas jurídi$\cos$ distintos ${ }^{21} \gg$

17 «El fundamento de validez de una norma solo puede encontrarse en la validez de otra norma. La norma que representa el fundamento de validez de otra es caracterizada, metafóricamente, como una norma superior en relación con una interior». KELSEN, Hans. Teoría pura del derecho. Edit. Porrúa. S.A., Séptima Edición, México, 1993, Pág. 201.

18 DWORKIN, RONALD. Los derechos en serio. Ariel Derecho. Séptima impresión, Barcelona 2009, Pág. 98.

19 RAWLS, John. La Justicia como equidad. Ediciones Paidós, Barcelona, 2002, pág. 38.

20 POUlANTZAS, Nicos. Poder Político y Clases Sociales en el Estado capitalista. Siglo XXI, México, 1999.

21 HABERMAS, Jurgen. Factibilidad y validez. Editorial Trotta, 1998, pág. 263. 
Ante tal realidad, algunos autores plantean utilizar las «lagunas e inconsistencias del derecho, que no puede ser técnica sino valorativa (política), entre diversas posibilidades. Cabe pues el uso alternativo del derecho si nos decantamos no por las interpretaciones convencionales sino por aquellas otras que favorecen los intereses de las clases subordinadas y el objetivo de la 'construcción de un nuevo poder democrático' que permita una gestión social del proceso de producción y distribución'. Dicho uso alternativo puede fundarse en los valores y principios democráticos y progresistas de la constitución formalmente reconoce (por ejemplo), el principio de la igualdad material, pero cuya realización efectiva es eludida por una legislación y una práctica interpretativa más conservadora inspirada en 'disvalolores' de signo contrario». ${ }^{22}$

Ello es posible debido a que el «derecho constitucional requiere en gran medida de interpretación, y esto significa que la interpretación debe transcender el sentido fijado en el texto, como lo Por eso para los interpretes de la constitución surge, una y otra vez, la pregunta acerca desde donde se debe determinar el sentido de la constitución. Se podría dudar acerca de si los procedimientos habituales de interpretación también son válidos aquí o si la distinción derecho constitucional/derecho normal también diferencia los aspectos de la interpretación. En este sentido- como dice Luhmann- se remite frecuentemente a estándares mas altos: morales y éticos; dado que de otra manera (es decir: inmanente al texto) no se podría alcanzar una decisión. Pareciera que los interpretes de la Constitución necesitan la referencia a un derecho más alto o algo mayor, para liberarse de sus inseguridades». ${ }^{23}$

\section{CONCLUSIONES}

El orden lógico-jurídico de la constitución de 1991 refleja en su estructura, control y valor sistémico de sus normas una teoría jurídica, pretendida paradigmáticamente como democrática (a la manera de Kelsen y Hart), que fortalece la vieja tradición del formalismo legal. Por otra parte, también se advierte en el orden jurídico-constitucional de valores morales, éticos, subjetivos y sociales que conllevan a la «aspiración» en un Estado social de derecho, más metafórico que real.

A partir del paradigma constitucional se dan diversas interpretaciones por los distintos actores sociales y jurídicos, destacándose los resultados jurídico-nor-

22 PEREZ LLEDÓ, Juan A. Teorías Críticas del Derecho. En «El Derecho y la justicia», edición de Ernesto Garzón Valdés, Editorial Trotta, Madrid, pág. 90.

23 LUHMANN, Niklas. El derecho de la sociedad. Herder. Universidad Iberoamericana. México.2002. Pág. 152. 
mativos y jurídico-material inmediatos, la institución investida constitucionalmente para ello, como es la Corte Constitucional, quien hace las interpretaciones y aplicaciones directas e inmediatas a partir del texto normativo superior y los ordenamientos internacionales, especialmente de derechos humanos, referenciados como valores y principios supraconstitucionales, más allá de la propia remisión por los artículos 93 y 94 de la Carta constitucional.

Por otra parte se ha desarrollado en el país una amplia discusión jurídica y filosófica desde los ambientes académicos, que busca reflexionar y explicar la legitimidad de un orden constitucional, desde la moral, el derecho, la ciencia política, en forma separada como lo plantea Bobbio, o integradoramente, como lo plantea Alexy, desde la teoría del derecho, la validez jurídica, moral o social de dicho orden: «la validez del derecho implica, en primer lugar, una validez jurídica que supone que la norma es dictada por el órgano competente y según un procedimiento previsto; en segundo lugar, una validez moral, que supone que la norma esta momentáneamente justificada y el sistema posee una pretensión de corrección en casos de normas injustas, y, en tercer lugar, una validez social que supone que la norma vale socialmente porque es obedecida y en caso de desobediencia se aplica una sanción» ${ }^{24}$.

Se advierte además en la cotidianidad una disgregación del orden político con la realidad social. Se parte en ocasiones de la legalidad del orden jurídico por el órgano que lo crea, o por la subordinación a un orden jerárquico, pero todo esto parece metafísico en términos kantianos; o por los principios y valores contenidos en las normas, pero en la práctica, en la vivencia, dichos contenidos de justicia material no producen los cambios que se pretenden y se define en las normas, pese a la existencia de procedimientos legales y constitucionales para exigir su realización.

Se pretende que el derecho pueda solucionar un orden social injusto, que las normas son expedidas por un órgano legítimo, y que incluso revisten de plena validez ya que son acatadas socialmente, y en caso contrario se puede aplicar una sanción. Sin embargo, pese a la existencia de una norma superior que predica la existencia de un Estado social de derecho, y el esfuerzo de la interpretación y aplicación que buscarían garantizar los principios políticos valores y contenidos de justicia social, existe una profunda desigualdad económica y social, y una profunda disgregación política de la mayoría que desdibuja el pretendido Estado social y derecho.

24 MEJIA QUINTANA, Oscar. Elementos para una reconstrucción del estatuto epistemológico de la filosofía del derecho. En «Humanitas» (No. 33) Nuevo León. Centro de Estudios Humanísticos, Universidad Autónoma de León, 2006, pág. 16. 
Ello recuerda los planteamientos marxistas, según los cuales el derecho es una superestructura que refleja los intereses de la clase dominante, y lejos está entonces, en representar los intereses de toda la sociedad, y por ende en solucionar los problemas de los excluidos. La ley es la concreción de la política, y refleja los intereses económicos y políticos de quienes la producen a través de los órganos del Estado. El Estado es la principal organización u aparato que tiene el propósito de arbitrar los conflictos para que la sociedad no se destruya. Para ello cuenta con los distintos órganos u aparatos, como son, entre otros, el congreso, los órganos de justicia, la fuerza pública, las cárceles, los medios de comunicación y hasta las diferentes iglesias defensoras del orden establecido.

Entre los instrumentos de conservación del orden jurídico-político, ante un ataque que haga peligrar la existencia del Estado, el ordenamiento jurídico prevé la declaratoria de un estado de excepción o un estado de sitio, que «consiste en la suspensión del ordenamiento vigente para garantizar su existen$\mathrm{cia}^{25}$ », según Giorgio Agamben, en que transfieren facultades del legislativo, y en ocasiones del poder judicial, al ejecutivo, de manera temporal para hacer frente al ataque, ya que si convierte en forma permanente adquiere la connotación de un dictadura o régimen totalitario, caso en el cual se destruyen los «principios del Estado constitucional democrático, entre otros el de la democracia, el de la separación de poderes y el de Estado de derecho» ${ }^{26}$ (Alexy).

El derecho es el principal instrumento normativo e ideológico de coerción, ordenes respaldadas con amenazas, al decir de HART, materializable a través de los órganos de represión del Estado. «Lo que generaliza entonces el poder de castigar no es la conciencia universal de la ley en cada uno de los sujetos de derecho, es la extensión regular, es la trama infinitamente tupida de los procedimientos panópticos» 27 . Es la extensión de la «disciplina-mecanismo: un diseño de coerciones sutiles que mejora el ejercicio del poder, volviéndolo más rápido, más ligero, más eficaz, denominado por Foucault como panoptismo, es decir, modelo de control dentro del panóptico, permanente, extendido a toda la sociedad.

En defensa de del orden jurídico, el Estado también tiene otros métodos más sofisticados que se aplican a través de la escuela y otros aparatos ideológicos,

25 AGAMBEN, Giorgio. Estado de excepción. Editorial Pre-textos, Valencia, 2004, pág. 49.

26 ALEXY, Robert. Teoría del discurso y derechos humanos. Universidad Externado de Colombia, Bogotá, 1995. Pág. 59.

27 FOUCAULT, Michel. Vigilar y Castigar, Siglo XXI de España Editores, Madrid, 1986 pág. 226. 
como los medios de comunicación social, los partidos políticos, las iglesias, los órganos de poder político, y un sinnúmero de organizaciones sociales, que difunden no solo el derecho, sino la disciplina, la moral, doctrinas políticas, todo tipo de creencias y supersticiones y pseudociencias, a través de las cuales se reproduce y apuntala la ideología dominante. «La creencia en el orden jurídico, tácitamente convenida- escribe Pierre Bourdieu- ${ }^{28}$ debe ser reproducida sin cesar y es una de las funciones del trabajo propiamente jurídico de codificación de las representaciones y de las prácticas éticas la de contribuir a fundar la adhesión de los profanos a los fundamentos mismos de la ideología profesional del cuerpo de juristas, es decir, a la creencia en la neutralidad u la autonomía del derecho y de los juristas»

El derecho día a día avanza y domina todos los espacios, sin resolver los problemas sociales básicos, pese a los postulados constitucionales. También avanza la represión abierta y sofisticada, y la sutil. Desde el Estado se vende la idea de que todo se resolverá a través de la norma jurídica, dentro de los causes legales. A cada problema planteado se expide una norma regulatoria. La academia, con su discusión a veces alejada de la realidad social, sobre el origen de la norma, sus características intrínsecas, y también sobre su contenido ético y sustantivo, pese a su propósito de acertar, conlleva también cierto grado de mistificación de la norma y el Estado como ente capaz de solucionar los problemas sociales.

Esa discusión semántica, teórica, al margen de las luchas sociales recuerda el apotegma de Marx en las Tesis sobre Feuerbach, según el cual, «los filósofos no han hecho más que interpretar de diversos modos el mundo, pero lo que se trata es de transformarlo» 29 .

Ni activismo jurídico ni la discusión académica por si solos, aunque no constituya tampoco su pretensión, son suficientes para transformar la realidad; pero las soluciones justas inmediatas a aliviar algún problema concreto, y la discusión teórica ayudar a delinear un camino hacia soluciones societales mas certeras, mediada por la acción política y la participación consciente e ilustrada de las mayorías, lo cual no deja de ser una verdad de Perogrullo, que sin embargo hay que resaltar.

28 BOURDIEU, Pierre. Elementos para la sociología del campo jurídico. En «La Fuerza del Derecho», Ediciones Uniandes- Instituo Pensar- Siglo del Hombre Editores, Bogotá, 2000. Pág. 207.

29 MARX, Carlos. Tesis sobre Feuerbach. En «Obras Escogidas en dos tomos» Editorial Progreso, Moscú, s.f. Pág. 403. 
El Estado que regula todas las formas de control social, es una maquina omnipresente en todas las relaciones sociales, económicas y culturales. No es posible -salvo en la utopía marxista- deshacerse de él. La constitución de 1991 plantea un Estado social de derecho con un amplio catálogo de derechos fundamentales, la totalidad de los cuales se han quedado en el papel. No se vislumbra una solución cercana a los problemas sociales que agobian a la nación.

Para algunos la solución pasa por una revolución, que nunca llega, y por el contrario ha ayudado a agravar los problemas del país. La revolución social concebida en los términos stalinistas destruyó la utopía y dejo de ser seductora para las masas y los intelectuales, ni se vislumbra hoy como una vía para salir del subdesarrollo con justicia social. A la sombra del conflicto armado avanzó el despojo de las tierras a millones de campesinos y se segó la vida de miles de colombianos. La mitad de los colombianos no creen en la política, el Estado, y son abstencionistas. Millones de refugian en privado en la religión. Los partidos oficialistas y tradicionales son maquinarias de captura del Estado para luego saquearlo y legislar en beneficio de los conglomerados económicos nacionales y globalizados, poniendo a su servicio la nación y los recursos naturales.

Pese al panorama pesimista, no puede predicarse el apoliticismo, ni la marginación ni el abandono de la lucha social, ni el desconocimiento absoluto del derecho. Tampoco se puede renunciar a la lucha política por el poder como lo hacen actuales movimientos sociales de protesta «indignados» $\mathrm{y}$ «ocupa», pese a los éxitos alcanzados en poco tiempo y la justeza de sus luchas contra las desigualdades del sistema económico y por la mejora para el 99\% de la población ${ }^{30}$, no se plantean por ahora actuar como una organización política tradicional.

Tal vez la solución se halle en las construcción de un movimiento social amplio, que represente las mayorías populares, a través de las movilizaciones reivindicatorias, como las de los estudiantes por el derecho a la educación, y de los indígenas y campesinos por la tierra, y la construcción de un movimiento político bajo las banderas de la justicia social, con vocación de poder, nada de lo cual se ha podido construir y que no constituye ninguna revelación decirlo.

La vía armada que buscaba la destrucción del ordenamiento jurídico-político y la construcción de un nuevo orden económico-social no logró el objetivo, la lucha se volvió endémica y un pretexto para la criminalización de la protesta,

30 http://actualidad.rt.com/actualidad/ee_uu/issue_34361.html 
causando por otra parte graves daños no solo en la estructura jurídica democrática exacerbando incluso la creación de organizaciones armadas ilegales ${ }^{31}$, deformaciones en la inversión pública que llegó a abarcar hasta una cuarta parte del presupuesto nacional desviando dichos dineros de la inversión social, dificultando la extracción de recursos minerales y explotación agrícola, la inversión extranjera y la expansión del capital, todo lo cual convirtió en una necesidad del Estado la solución del conflicto armado que llevó a buscar su terminación a través de la negociación política.

La construcción de una democracia social consensuada pasa por el reconocimiento de los intereses de la mayoría y la integración en el respeto de las minorías. Con Alf Ross, y sus teorías del realismo jurídico, «la justicia debe armonizar los deseos, pretensiones e intereses en conflicto en la vida social de la comunidad. Adoptando que todos los problemas jurídicos son problemas de distribución, el postulado de justicia equivale a una demanda de igualdad en la distribución y el reparto de las ventajas o cargas. En este sentido la justicia es la igualdad $»^{32}$.

Finalmente habría que decir, que acuerdos alcanzados en La Habana el 24 de Agosto de 2016, reformulados a partir del revés obtenido en el plebiscito del 2 octubre de 2016 que los improbó por un margen del 0.4 por ciento ${ }^{33}$, y nuevamente rubricados el 24 de noviembre 2016 para ser ratificados por el Congreso, con sus contenidos de reforma agraria, reivindicación de derechos de indígenas, víctimas, mujeres, ampliación de las garantías de participación política, si bien no resuelven los problemas económicos y sociales de las mayorías, de realizase lo acordado, si constituyen un avance en la vía de solución de dichos problemas; y la terminación del conflicto armado la eliminación de un «obstáculo» que se venía utilizando para reprimir la protesta social, permitiendo la ampliación de las lucha social y política. La política se reivindica nuevamente como el escenario propio de la confrontación de ideas a elevar a norma jurídica cuya eficacia no se garantiza por las razones expuestas en este ensayo.

31 Los paramilitares fueron creados bajo la denominación de grupos de autodefensa campesina por el decreto de estado de sitio 3398 de 1965 del 24 de diciembre de 1965, convertido luego en norma permanente por la ley 48 de 1968. Esta estructuras paramilitares fueron inspiradas en la doctrina de seguridad nacional.

32 FERREIRA OSPINO, Javier. La política de la memoria: prolegómenos a una teoría de la justicia de las víctimas. En «perspectivas de la Filosofía del derecho y las teorías jurídicas contemporáneas. Facultad de Filosofía, Universidad Libre, Bogotá, 2011, pág. 339.

33 El SI a favor de la aprobación de los acuerdos FARC-Gobierno Nacional obtuvo 6.397.482 con el 49.78 \%; el no OBTUVO 6.431 .376 con el 50.21\%. Registraduría del Estado Civil: http:/ / plebiscito.registraduria.gov.co/99PL/DPLZZZZZZZZZZZZZZZZZ_L1.htm. Consultada el 25 de Noviembre de 2016. 


\section{REFERENCIAS}

AGAMBEN, Giorgio (2004). Estado de excepción. Editorial Pre-textos, Valencia.

ALEXY, Robert (1995). Teoría del discurso y derechos humanos. Universidad Externado de Colombia, Bogotá.

BOURDIEU, Pierre (2000). Elementos para la sociología del campo jurídico. En «La Fuerza del Derecho», Ediciones Uniandes- Instituto Pensar- Siglo del Hombre Editores, Bogotá.

CARBONEL, Miguel (2006). Neoconstitucionalismo. Trotta, Madrid.

CHOMSKY, Noam (1992). El miedo a la Democracia. Editorial Crítica, Barcelona.

CISNEROSFARÍAS, Germán (2000). Teoría del Derecho. Editorial Trillas, 2da edición, México.

CORTE CONSTITUCIONAL, C 276 de 1993. 22 de julio de 1993. M.P. VLADIMIRO MESA.

DEZALAY, Yvets y TRUBEK, David M. (1994). La reestructuracion global y el derecho. En: «pensamiento juridico». Universidad Nacional de Colombia, No. 1.

DWORKIN, RONALD (2009). Los derechos en serio. Ariel Derecho. Séptima impresión, Barcelona.

DWORKIN, Ronald (1997). Los derechos en serio. Traducción de Marta Guastavino. Editorial Ariel, 3ra reimpresión, Barcelona.

FOUCAULT, Michel (1986). Vigilar y Castigar. Siglo XXI de España Editores, Madrid.

HABERMAS, Jurgen (1998). Factibilidad y validez. Editorial Trotta.

HART, H.L.A. (FALTA AÑO). El concepto de Derecho, Abeledo Perrot, Buenos Aires.

KELSEN, HANS (1993). Teoría Pura del Derecho, Edit. Porrúa. S.A., Séptima Edición, México.

KELSEN, Hans (2007). ¿Qué es la Teoría pura del derecho? Distribuciones Fontamasra S.A., Doceava reimpresión, México.

KELSEN, Hans (1993). Teoría Pura del Derecho. Edit. Porrúa. S.A., Séptima Edición, México. 
LUHMANN, Niklas (2002). El derecho de la sociedad. Herder. Universidad Iberoamericana. México.

MARX, Carlos (FALTA AÑO). Tesis sobre Feuerbach. En «Obras escogidas en dos tomos» Editorial Progreso, Moscú, s.f

MEJIA QUINTANA, Oscar (2006). Elementos para una reconstrucción del estatuto epistemológico de la filosofía del derecho. En «Humanitas» (No. 33) Nuevo León. Centro de Estudios Humanísticos, Universidad Autónoma de León.

MOTTA, Cristina (1995). Ética y Conflicto. Uniandes y Tercer Mundo Editores, primera edición, Bogotá.

PEREZ LLEDÓ, Juan A. (FALTA AÑO). Teorías Críticas del Derecho. En «El Derecho y la justicia». Edición de Ernesto Garzón Valdés, Editorial Trotta, Madrid.

POUlANTZAS, Nicos (1999). Poder Político y Clases Sociales en el Estado capitalista. Siglo XXI, México.

RAWLS, John (2002). La Justicia como equidad. Ediciones Paidós, Barcelona.

REGISTRADURIA DEL ESTADO CIVIL. http://plebiscito.registraduria.gov. co/99PL/ DPLZZZZZZZZZZZZZZZZZ_L1.htm.

SCHMILL O., Ulises (1996). El Positivismo Jurídico. En «El Derecho y la Justicia». Enciclopedia Iberoamericana de Filosofía. Editorial Trotta, Madrid.

SCHMITT, Carl (1996). Sobre los tres modos de pensar la ciencia jurídica. Trad. Monserrat Herrera, Técnos, Madrid. 